\title{
Calculating Overall Subsidies for Special Education by Acquiring Information from Individual Students
}

\author{
Hsuan-Fu Ho ${ }^{1}$, Sheng-Ju Chan ${ }^{2}$, Liang-Ching Lin $^{3} \&$ Pi-Yu Chen ${ }^{4}$ \\ ${ }^{1}$ Graduate Institute of Educational Administration and Policy Development, National Chiayi University, Taiwan \\ ${ }^{2}$ Department of Education, National Chong Cheng University, Taiwan \\ ${ }^{3}$ Department of Education, Chiayi City Government, Taiwan \\ ${ }^{4}$ Central Region Office, Ministry of Education, Taiwan \\ Correspondence: Hsuan-Fu Ho, Graduate Institute of Educational Administration and Policy Development, \\ National Chiayi University, 85 Wenlong Minshong, Chiayi County, Taiwan. Tel: 11-886-922-910-101. E-mail: \\ hfho2264780@gmail.com
}

Received: November 4, 2013 Accepted: December 4, 2013 Online Published: December 18, 2013

doi:10.5539/ies.v7n1p60

URL: http://dx.doi.org/10.5539/ies.v7n1p60

\begin{abstract}
The ideal of public education is to provide each student with equal opportunity to effectively learn what he or she needs to learn. However, because students are born unequally, additional resources should be allocated for assisting students with learning disadvantages. In order to gain a more accurate understanding of the actual needs of different types of special education students, questionnaires were delivered to 840 students in 280 classes in various parts of Taiwan. The main difference between this research and previous studies in the world is that in this study the students themselves are taken as the sample population, each providing responses with assistance from their teachers, so that the data gained from each questionnaire represents an individual student's unique needs. The overall weighting calculated from this new method of research is 2.20 , which is similar to the results of many studies that were using different approaches.
\end{abstract}

Keywords: special education, school finance, subsidies, fiscal weighting

\section{Background}

The ideal of public education is to provide each student with the opportunity to effectively learn what he or she needs to learn. However, by this definition, special education students are unable to effectively learn in an ordinary classroom environment. Thus, ensuring special education students' right to an education requires providing them with separate classes and other support (Alexander \& Salmon, 1995). According to the "vertical equity" concept of educational finance, because students are unequal, they require unequal treatment. Therefore, additional resources should be allocated for assisting students with learning disabilities (Ko, 2006; Rodriguez, 2004). Although the cost of special education is inevitably much higher than that of ordinary education, it still must conform to the performance principle with respect to individuals, social justice, and rate of return (Nathanson, 1998).

Ever since the General Assembly of the United Nations adopted the Universal Declaration of Human Rights in 1948, the educational rights of those with a physical or mental disability have been receiving increasing importance around the world. This is especially true in the West, where the provision of adequate special education is widely accepted as one of the goals of public education. Special education in Taiwan began to receive increasing importance in 1979 with the promulgation of the National Education Act, which states that appropriate education and skills training should be made available to all children, whether gifted or handicapped. In 1984 the Legislative Yuan promulgated the Special Education Act, further clarifying the government's responsibility for providing special education. In 1997 the budget for special education found a firm footing in the form of an amendment made to the Special Education Act stipulating that the amount of public funds allocated by the central government for special education should not be less than three percent of the total education budget; for local governments the figure was set at five percent.

Yet, there remain some doubts as to the ability of the special education budget to meet the actual requirements of special education students. Is there any difference in the cost of educating students of different types and degrees 
of disability? If so, what is the difference? In one of the few studies carried out in Taiwan on these interrelated questions, Ho and Chen (2011) present formula for calculating the cost of special education. In their study, the estimated costs of special education were calculated according to what special education teachers considered to be required by the average special education student in terms of teachers, assistance devices, and administrative support. While this method of cost calculation is widely used throughout the world, because it doesn't take into account the particular requirements of individual students, it's not possible to use the data thus obtained to carry out a more precise statistical analysis. Thus there are doubts as to its degree of accuracy.

In order to gain a more accurate understanding of the actual needs of different types of special education students, in the present study the students themselves are taken as the sample population, providing responses with assistance from their teachers. The data thus obtained can be used to carry out a more detailed statistical analysis, making it possible to calculate a percentage and the significance of differences for each requirement. It also becomes possible to use statistical inference to estimate the number of personnel required throughout Taiwan for each item. The budget estimated in this way can be expected to be more accurate than one based on the rather arbitrary estimates made by special education professionals or scholars.

Based on the above considerations, the four main goals of this research are as follows:

(1) To determine the additional requirements of special students with respect to category and degree of disability.

(2) To calculate the budget necessary for meeting these requirements.

(3) To carry out an Analysis of Variance (ANOVA) on the additional amount of funding required by special education students of different categories and degrees of disability.

(4) To calculate the weighting of the budgetary requirements for special students with respect to category and degree of disability.

\section{Review of the Related Literature}

Funds for special education are provided on the principle of a higher level department allocating subsidies to one on a lower level. In addition to reducing the financial burden at the local level, such subsidies help to mitigate inequities in education which arise due to the budgetary disparity which exists between different localities (Ko, 2006; Springer, Liu, \& Guthrie, 2009). However, if the amount of such subsidies is far from the actual requirements, then neither of these goals will be attained and much of the funding will be wasted (Ho \& Chen, 2011). For this reason, this section focuses on the essential concepts and principles related to allocating a budget for special education, as well as the subsidy formulas already in use.

\subsection{Education Finance and Vertical Equity}

Equity is one of the most important principles of education finance. The general understanding of equity is that everybody should be treated equally. However, for those with special needs, equal treatment amounts to neglect. Odden and Picus (2004) assert that a child-centered approach to education finance is one which strives for horizontal equity, vertical equity, fiscal neutrality, and effectiveness. Of these, vertical equity means the unequal treatment of unequals, whereby students are divided into various categories, with the most disadvantaged groups receiving the most resources; this is true equality. The position that extra funds should be provided for special education is based on the principle of vertical equity.

Most scholars of education finance agree that certain groups of students require additional educational resources. Nonetheless, there is little agreement as to which groups of students require additional resources and how much additional resources they require (Berne \& Stiefel, 1999). In the US, it's mainly the federal and state governments which provide subsidies and determine the eligibility of special education students for additional resources; the standpoint of the federal government is that of human rights, while that of the state governments is education. Although it had long been recognized in the US that equity in education requires providing an adequate budget for special education, this sentiment wasn't really put into effective action until 1975 with the passage of the Education for All Handicapped Children Act (PL94-142). This Act guaranteed funding for special education from both federal and state sources, and can be seen as the precursor of the 1990 Individuals with Disabilities Education Act (IDEA), which guaranteed free and adequate education to all special education students. Most of the significant research on funding for special education has been conducted since the passage of IDEA.

What, then, is the procedure by which these subsidies are allocated? While the formulas used by different states are not identical, they can generally be classified into two types: weighting formulas and categorical formulas, with a number of states using a formula which is a combination of these two types (Gold, Smith, \& Lawton, 
1995). Odden and Picus (2004) found that most of the federal subsidies for special education are provided as a per pupil flat grant determined by the number of students. As for state and local subsidies, these can generally be classified as either full state funding or state-local cost sharing. However, since few state governments are able to independently bear the high cost of special education, the cost is usually split between the state and local government.

\subsection{Determining the Adequate Amount for Special Education Subsidies}

Because of the high cost of special education and the overall limitations of funds for education, providing additional funding for special education inevitably comes at the cost of reducing the amount of funding available for ordinary education (Parrish, 2000). Thus, any research on funding for special education must necessarily begin with an assessment of just how much education should be provided for special education students. Nathanson (1998) made a comparison of several models for providing subsidies for special education:

(1) Entitlement theory is based on the free market principle and asserts that all transactions are carried out for the sake of self-benefit. As such, education should be free of government interference and should not be treated as a form of social welfare. Schools should be free to make their own decisions as to whether to provide special education, and, should they decide to do so, at what cost. If the cost is found to be reasonable to the families of special education students, then they will enroll their children in that school.

(2) Utilitarianism is based on the idea that, regardless of how public funds are distributed, the main goal is to bring the greatest possible practical benefit to society as a whole. If it's found that educating special education students is of benefit to society, then the government should allocate funds for doing so. On the other hand, if such education is not found to be cost effective, then the government should invest the funds in something more worthwhile.

(3) The difference principle is based on the premise that in every aspect of society there will be those who are advantaged and those who are disadvantaged. Thus, in order to achieve the greatest possible degree of social equity, the disadvantaged should receive preferential treatment. Moreover, funds should not be shifted from the disadvantaged to the advantaged unless doing so will be of benefit to the disadvantaged.

(4) The decent-level theory is based on the premise that all students should be provided with an education which meets a certain standard. If some students require extra help to reach this standard, then the government should provide all the extra funding required for helping them do so. After doing so, any funds that are left over can be allocated in other ways.

(5) The maximum feasibility theory is essentially a contingency theory of the decent-level theory, to be applied if the government is unable to provide the funds required to reach the established standards, due to either economic downturn or if the prevailing standards of what constitutes a decent level of education are extremely high. In such situations the government should not be expected to do what is beyond its ability, but should still do as much as possible to provide an adequate level of education for students with special needs.

Each of these models for providing subsidies for special education has its supporters, as well as its strengths and weaknesses. In the education field, entitlement theory is the least acceptable of these models, because of the general agreement that the government should take responsibility for providing education, especially when it is compulsory. Although utilitarianism aims to benefit society as a whole, because it advocates doing so in a way which ignores the human rights of certain minority groups, it also doesn't have much appeal to the education field, nor to the general public. Although the difference principle advocates giving priority to the education of the disadvantaged elements of society, because doing so would be to the detriment of ordinary students and the overall quality of education, it's not very feasible.

Of these models, the decent-level theory is the one which is most widely accepted by contemporary scholars of education, for it guarantees all students the right to an education while guarding against the deleterious effect on the overall quality of education which would result from a rapid increase in the cost of special education. The main problem with this model is the lack of consensus as to just what is meant by a decent level of education. For these reasons, the approach most in line with the current trends in education is to adopt the decent-level theory augmented by the maximum feasibility theory.

But just how are we to calculate the amount of additional funding required for students with different types and degrees of disability? Chambers (1980) found that the cost of special education can be calculated by adding together three items: 1) the basic cost of educating an ordinary student; 2) the extra costs for all students (substitute teachers, remedial classes, etc.); and 3) the extra costs for special education students. Chambers also points out that in making such an estimate, one should not completely rely on data currently available, since it is 
likely to be outdated. Greene (2007) asserts that even more important than the amount of the subsidies is determining which students should be eligible for special education. This is because laxness in eligibility standards leads to a large increase in the number of special education students, and these results in budget deficits which inevitably lower the overall quality of education.

\subsection{Calculating the Weightings}

The first step in calculating the cost of special education is to determine the extra services required by special education students. Hartman (1981) contends that the requirement differential within a given category of special education is greater than that which exists between categories. For this reason he asserts that calculating a budget for special education should take into consideration not only the differences between different categories of disability, but should also take into account the differences within each category.

This method of calculation has long been used in the US. Using the weighting formula most commonly used in the US (the expenditure for each special education student divided by the expenditure for each ordinary student), Kakalik et al. (1981) calculated the weighting for each category and degree of disability, arriving at an overall weighting of 2.85. Parrish, Matsumoto, and Fowler (1995) found the weighting for special education students to be about 2.3, and the weighting for economically disadvantaged students to be about 2.0. Chambers, Levin, and Shambaugh (2010) studied the weighting formulas used in two school districts in California and concluded that the more the formula is able to represent the requirements of individual students, the greater the degree of fiscal equity. In light of the preceding, we set out to determine the additional funding required for each special education student, as well as the weighting for each of the six categories and three degrees of disability.

\section{Research Design}

We first conducted a survey to determine the requirements of special education students in Taiwan. The results of the survey were used to calculate a nationwide weighting which can used in formulating the special education budget.

\subsection{Research Participants}

A questionnaire was administered to special education students at public primary schools. The students provided responses with assistance from their teachers, as necessary; this was the most distinctive part of the research design. The teachers were selected to administer the questionnaire and provide assistance because they are already very familiar with their students and their requirements, and also because they are familiar with filling out such questionnaires. We used the data published by the MOE on special education classes in Taiwan to create a random sample. Each teacher in the sample was asked to select the three students they were most familiar with and have the students fill out the questionnaire.

\subsection{Research Instruments}

The main research tool used in this study was the self-designed Questionnaire on the Educational Requirements of Special Education Students. A pilot version was first created and then revised according to the feedback provided by one scholar of education, one physician, one special education teacher, one special education assistant, and two government officials. The questionnaire was divided into background information (gender, age, and disability category and degree); assistive device requirements; and staff requirements. The second section consisted of a list of assistive devices, each of which was accompanied by two possible responses: "required" and "not required." The third section consisted of a list of the various personnel required by special education students, and the respondents were asked to indicate the number of hours each was required in an average week.

\subsection{Sample Design}

Using data provided by the MOE, 840 special education students in 280 classes in various parts of Taiwan were selected, and the teacher of each class was sent the questionnaire and asked to administer it to three students. A total of 620 questionnaires were returned, a retrieval rate of 74 percent. After eliminating incomplete questionnaires and those for students whose main disability was not included in this study, there remained 554 valid questionnaires; these were used to conduct the statistical analysis and to calculate the budget.

\subsection{Calculating Cost and Weighting}

In this part of the study we calculated the total amount spent on each special requirement. We first determined the cost of each assistive device required by special education students. Next, after determining how many years each assistive device could be used, we divided the cost by its projected life span to obtain the annual cost. For the personnel costs, we used the information obtained from the questionnaire to determine the number of hours each student required each type of staff member per year, and then multiplied this by that staff member's hourly 
pay rate to obtain the annual cost. Finally, we combined the cost of the assistive devices and personnel requirements to obtain the overall annual additional costs.

The weighting was determined by combining the additional expenditures required for each special education student with the average expenditure for each ordinary student, and then dividing by the average expenditure for each ordinary student. The weighting thus obtained indicates the ratio of the extra funding required for special education students, and is similar to those used by many states in the US.

\section{Results}

A total of 840 questionnaires were sent out, 620 of which were returned within one month. After eliminating invalid questionnaires, there remained a total of 554 valid questionnaires. As for the participants' background variables, 61 percent were male and 39 percent were female; 28 percent were in the first or second year of elementary school, 34 percent were in the third or fourth year, and 38 percent were in the fifth or sixth year. As for degree of disability, 27 percent were mildly disabled, 32 percent were moderately disabled, and 41 percent were severely disabled. As for category of disability, 10 percent were visually impaired, 8 percent were orthopedically impaired, 27 percent were intellectually impaired, 12 percent were hearing impaired, 16 percent were autistic, and 27 percent had multiple disabilities.

\subsection{Personnel Expenses}

The next step was to calculate the projected additional personnel expenses for each category and degree of disability. The highest personnel expenses were for autistic students, while the lowest were for those with a visual or hearing impairment. As for degree of disability, for the most part, in each category the highest personnel expenses were for the severely disabled, while the lowest were for the mildly disabled. However, for the orthopedically disabled, the additional personnel costs were about the same for severe and moderate degrees of disability (Table 1).

Table 1. Average personnel expenses according to category and degree of disability (US\$)

\begin{tabular}{cccccccc}
\hline \multicolumn{6}{c}{ Visual Orthopedic Intellectual Hearing Autistic Multiple Mean } \\
\hline Mild & 1,250 & 1,940 & 3,863 & 1,138 & 2,896 & 2,899 & 2,331 \\
Moderate & 1,439 & 4,988 & 4,862 & 2,176 & 5,924 & 5,052 & 4,074 \\
Severe & 4,068 & 5,019 & 7,927 & 3,507 & 8,344 & 6,924 & 5,965 \\
Mean & 2,252 & 3,982 & 5,551 & 2,274 & 5,721 & 4,958 & 4,123 \\
\hline
\end{tabular}

\subsection{Assistive Device Expenses}

The highest projected expenditures on assistive devices were for students with a visual disability, while the lowest were for autistic students and those with an intellectual disability. As for degree of disability, for the most part, in each category the highest personnel expenses were for the severely disabled, while the lowest were for the mildly disabled. However, for the hearing disabled, the expenses for assistive devices were about the same for severe and moderate degrees of disability (Table 2).

Table 2. Average expenses for assistive devices according to category and degree of disability (US\$)

\begin{tabular}{cccccccc}
\hline \multicolumn{1}{c}{ Visual Orthopedic Intellectual Hearing Autistic Multiple Mean } \\
\hline Mild & 389 & 93 & 134 & 479 & 139 & 164 & 233 \\
Moderate & 640 & 469 & 247 & 502 & 228 & 370 & 409 \\
Severe & 825 & 634 & 393 & 524 & 500 & 827 & 617 \\
Mean & 618 & 398 & 258 & 502 & 289 & 454 & 420 \\
\hline
\end{tabular}

\subsection{Total Additional Expenses}

The total additional expenses for each category and degree of disability were obtained by adding together the expenses for personnel and assistive devices. The results indicate that autistic students required the highest 
overall additional expenses, while those with hearing or visual impairments required the least. As for degree of disability, for the most part, in each category the highest personnel expenses were for the severely disabled, while the lowest were for the mildly disabled. However, for the orthopedically disabled, the total expenses were about the same for severe and moderate degrees of disability (Table 3 ).

Table 3. Average total expenses according to category and degree of disability (US\$)

\begin{tabular}{cccccccc}
\hline \multicolumn{6}{c}{ Visual Orthopedic Intellectual Hearing Autistic Multiple Mean } \\
\hline Mild & 1,640 & 2,033 & 3,997 & 1,617 & 3,034 & 3,063 & 2,564 \\
Moderate & 2,078 & 5,457 & 5,109 & 2,678 & 6,152 & 5,423 & 4,483 \\
Severe & 4,892 & 5,653 & 8,320 & 4,031 & 8,843 & 7,751 & 6,582 \\
Mean & 2,870 & 4,381 & 5,809 & 2,776 & 6,010 & 5,412 & 4,543 \\
\hline
\end{tabular}

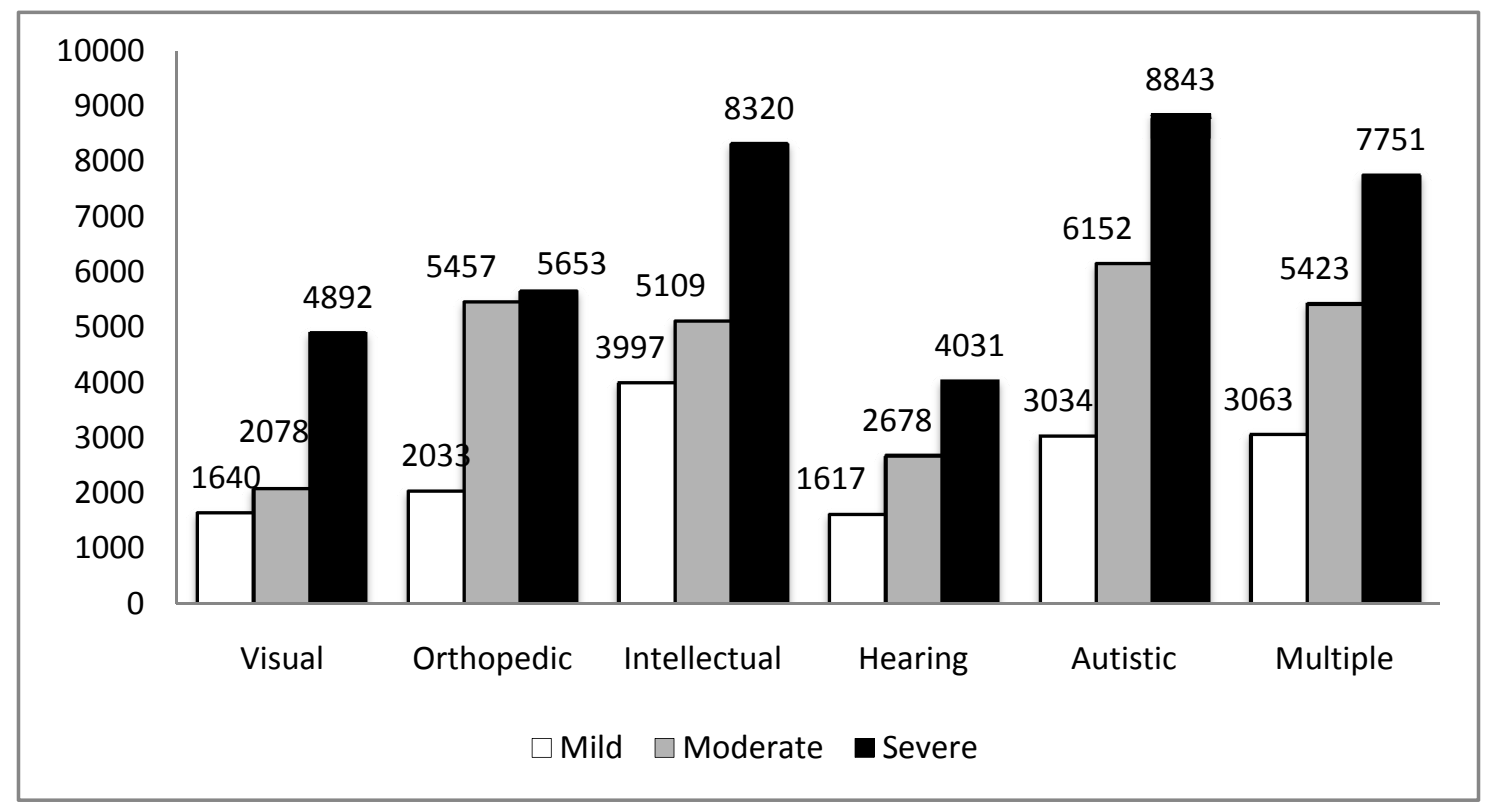

Figure 1. Average total expenses according to category and degree of disability (US\$)

\subsection{ANOVA of the Degrees of Disability}

We next used one-way ANOVA to test for any significant differences between the expenses with respect to degree of disability. The results indicate that for each degree of disability there was a significant difference between personnel expenses, assistive device expenses, and overall expenses. The highest personnel expenses were for the severely disabled, while the lowest were for the mildly disabled. 
Table 4. ANOVA of expenses for personnel and assistive devices for the three degrees of disability

\begin{tabular}{ccccccc}
\hline Expense & Degree & No. & Mean & F-value & Significance & Sheffé \\
\hline \multirow{3}{*}{ Personnel } & 1 Mild & 146 & 86963 & & & \\
& 2 Mod. & 179 & 151568 & 17.76 & .000 & $3>2>1$ \\
& 3 Severe & 229 & 207725 & & & \\
\hline \multirow{3}{*}{ Assistive Devise } & 1 Mild & 146 & 6150 & & & \\
& 2 Mod. & 179 & 10411 & 63.76 & .000 & $3>2>1$ \\
& 3 Severe & 229 & 20670 & & & \\
\hline \multirow{2}{*}{ Total } & 1 Mild & 146 & 93113 & & & \\
& 2 Mod. & 179 & 161979 & 63.76 & .000 & $3>2>1$ \\
& 3 Severe & 229 & 228395 & & & \\
\hline
\end{tabular}

A comparison of the six categories of disability reveals that they differ with respect to personnel expenditures, assistive device expenditures, and total expenditures. The personnel expenditures for students with multiple disabilities were much higher than those for students with visual, orthopedic, or intellectual disabilities. The assistive device expenditures for students with an intellectual disability were lower than for those with visual, orthopedic, listening, or multiple disabilities; and the assistive device expenditures for students with visual or multiple disabilities were higher than those for autistic students. Finally, the total expenditures required for students with multiple disabilities were higher than those for all the other categories of disability.

Table 5. Comparison of expenditures for the six categories of disability

\begin{tabular}{|c|c|c|c|c|c|c|}
\hline & Category & No. & Mean & F-value & Significance & Sheffé \\
\hline \multirow{6}{*}{ Personnel } & 1 Visual & 55 & 78404 & \multirow{6}{*}{10.47} & \multirow{6}{*}{.000} & \multirow{6}{*}{$6>1,3,4$} \\
\hline & 2 Ortho. & 45 & 131516 & & & \\
\hline & 3 Intel. & 151 & 144564 & & & \\
\hline & 4 Hear. & 70 & 6680 & & & \\
\hline & 5 Aut. & 88 & 170092 & & & \\
\hline & 6 Mult. & 152 & 238560 & & & \\
\hline \multirow{6}{*}{ Assistive Devices } & 1 Visual & 55 & 19142 & \multirow{6}{*}{22.24} & \multirow{6}{*}{.000} & \multirow{6}{*}{$\begin{array}{c}1,2,4,6>3 \\
1,6>5\end{array}$} \\
\hline & 2 Ortho. & 45 & 13862 & & & \\
\hline & 3 Intel. & 151 & 6420 & & & \\
\hline & 4 Hear. & 70 & 15241 & & & \\
\hline & 5 Aut. & 88 & 8536 & & & \\
\hline & 6 Mult. & 152 & 20479 & & & \\
\hline \multirow{6}{*}{ Total } & 1 Visual & 55 & 97547 & \multirow{6}{*}{10.59} & \multirow{6}{*}{.000} & \multirow{6}{*}{$6>1,2,3,4,5$} \\
\hline & 2 Ortho. & 45 & 145379 & & & \\
\hline & 3 Intel. & 151 & 150984 & & & \\
\hline & 4 Hear. & 70 & 91921 & & & \\
\hline & 5 Aut. & 88 & 178628 & & & \\
\hline & 6 Mult. & 152 & 259040 & & & \\
\hline
\end{tabular}




\subsection{Calculating the Weighting}

In the final step we calculated the weighting with respect to both category and degree of disability. The weighting was determined by combining the average annual additional expenditures required for each special education student with the average annual expenditure for each ordinary student, and then dividing by the average annual expenditure for each ordinary student (in 2010 this was US\$3,794 for each primary school student).

$\mathrm{W}_{\mathrm{ij}}=\left(\mathrm{S}_{\mathrm{ij}}+\mathrm{G}\right) / \mathrm{G}$

$\mathrm{W}_{\mathrm{ij}}=\mathrm{i}=$ Weighting for category-j special education students with a degree-i disability.

$\mathrm{S}_{\mathrm{i} j}=\mathrm{i}=$ Average annual additional expenditures required for category- $\mathrm{j}$ special education students with a degree- $\mathrm{i}$ disability.

$\mathrm{G}=$ Average annual expenditure for each ordinary student.

Table 6. Weighting for each category and degree of disability

\begin{tabular}{|c|c|c|c|c|c|c|c|}
\hline & \multicolumn{7}{|c|}{ Visual Orthopedic Intellectual Hearing Autistic Multiple Mean } \\
\hline Mild & 1.43 & 1.54 & 2.05 & 1.43 & 1.80 & 1.81 & 1.68 \\
\hline Moderate & 1.55 & 2.44 & 2.35 & 1.71 & 2.62 & 2.43 & 2.18 \\
\hline Severe & 2.29 & 2.49 & 3.19 & 2.06 & 3.33 & 3.04 & 2.73 \\
\hline Mean & 1.76 & 2.15 & 2.53 & 1.73 & 2.58 & 2.43 & 2.20 \\
\hline
\end{tabular}

\section{Conclusion and Recommendations}

The main goal of this research was to develop a more accurate method for calculating the expenditures required for special education in Taiwan. The main difference between this research and previous studies is that in the present study the students themselves are taken as the sample population, providing responses with assistance from their teachers. The budget estimated in this way can be expected to be more accurate than one based on the rather arbitrary estimates made by scholars. Nonetheless, the method used in the present study provides more detailed information on different types of students, thereby increasing the accuracy and making it possible to carry out a variety of additional statistical computations.

The overall weighting obtained in this way was 2.20 , similar to the overall weighting of 2.85 obtained by Kakalik et al. (1981), and very close to the overall weighting of 2.3 obtained by Parrish, Matsumoto, and Fowler (1995).

The results of ANOVA indicate that there is a significant difference in the amount of additional expenditures required by students belonging to different disability categories; this is something the government should take into account when allocating subsidies for special education. The results of ANOVA also show that all three types of expenses (personnel, assistive devices, and total) were highest for the severely disabled, and lowest for the mildly disabled. This is in agreement with Hartman (1981), who contends that the requirement differential within a given category of special education is greater than that which exists between categories. Thus, the allocation of government subsidies for special education needs to take into account the different funding requirements with respect to category and degree of disability. Otherwise, certain types of students will end up being over funded, while others will end up being under funded.

Despite the great care with which this research was undertaken, a number of difficulties remain unsolved. For example, because the distribution in terms of both category and degree of disability was highly uneven at the schools included in this study, it wasn't possible to use proportional sampling to obtain a representative number of students for each category and degree of disability. For this reason, the proportions of the categories and degrees of disabilities of our sample may not be highly representative of the actual proportions. We thus recommend that future studies on this topic make every effort to increase the representativeness of the sample.

\section{References}

Alexander, K., \& Salmon, R. G. (1995). Public school finance. Boston, MA: Allyn \& Bacon.

Berne, R., \& Stiefel, L. (1999). Concepts of school finance equity. In H. Ladd, R. Chalk, \& J. Hansen (Eds.), Equity and adequacy in education finance: Issues and perspectives (pp. 7-33). Washington, DC: National 
Academies Press.

Chambers, J. G., Levin, J. D., \& Shambaugh, L. (2010). Exploring weighted student formulas as a policy for improving equity for distributing resources to schools: A case study of two California school districts. Economics of Education Review, 29(2), 183-300.

Gold, S., Smith, D., \& Lawton, S. (1995). Public school finance programs of the United States and Canada, 1993-94. Albany, NY: American Education Finance Association and the Nelson A. Rockefeller Institute of Government.

Green, J. P. (2007). Fixing special education. Peabody Journal of Education, 82(4), 703-723. http://dx.doi.org/10.1080/01619560701603213

Hartman, W. T. (1981). Projecting special education costs. Stanford, California: Stanford University, Institute for Research on Educational Finance and Governance.

Ho, H., \& Chen, P. (2011). Revamping the funding formula for special education programs in Taiwan. Asia Pacific Education Review, 12(1), 143-148.http://dx.doi.org/10.1007/s12564-010-9110-4

Kakalik, J., Furry, W. S., Thomas, M. A., \& Carney, M. F. (1981). The cost of special education. Santa Monica, CA: The RAND Corporation.

Ko, J. W. (2006). The impact of new funding formula on school finance equity in Missouri. Education, 126(3), $559-568$.

Nathanson, S. (1998). Are special education programs unjust to nondisabled children? Justice, equality, and the distribution of education. Journal of Education, 180(2), 17-40.

Odden, A. R., \& Picus, L. O. (2004). School finance: A policy perspective. New York: McGraw Hill.

Parrish, T. (2000). Restructuring special education funding in New York to promote the objective of high learning standards for all students. Economics of Education Review, 19, 431-445.

Parrish, T., Matsumoto, C., \& Fowler, W. (1995). Disparities in public school district spending: 1989-90. Washington, DC: US Government Printing Office.

Rodriguez, G. M. (2004). Vertical equity in school finance and the potential for increasing school responsiveness to student and staff needs. Peabody Journal of Education, 79(3), 7-30.

Springer, M. G., Liu, K., \& Guthrie, J. W. (2009). The impact of school finance litigation on resource distribution: A comparison of court-mandated equity and adequacy reforms. Education Economics, 17(4), 421-444. http://dx.doi.org/10.1080/09645290802069269

\section{Copyrights}

Copyright for this article is retained by the author(s), with first publication rights granted to the journal.

This is an open-access article distributed under the terms and conditions of the Creative Commons Attribution license (http://creativecommons.org/licenses/by/3.0/). 